East African Medical Journal Vol. 85 No. 11 November 2008

PNEUMATIC REDUCTION OF INTUSSUSCEPTION IN CHILDRENAT THE KOMFOANOKYE HOSPITAL, KUMASI, GHANA

F. A. Abantanga, MD, Cert. Paed. Surg., PhD (Paed. Surg), FWACS, FGCS, Associate Professor, Department of Surgery, School of Medical Sciences, College of Health Sciences, Kwame Nkrumah University of Science \& Technology, Kumasi, Ghana and Directorate of Surgery, Komfo Anokye Teaching Hospital, M. Amoah, MBChB, Senior Resident, Directorate of Surgery, A. O., Adeyinka, MBBS, FWACS, FMCR (Nigeria), Senior Lecturer, Diagnostics Directorate, Radiology Unit and B. Nimako, MBChB, Chief Resident and K. P. Yankey, MBChB, Resident, Komfo Anokye Teaching Hospital, Kumasi, Ghana, Komfo Anokye Teaching Hospital, Kumasi, Ghana.

Request for reprints to: Prof. F. A. Abantanga, Department of Surgery, Komfo Anokye Teaching Hospital, P. O. Box 1934, Kumasi, Ghana

\title{
PNEUMATIC REDUCTION OF INTUSSUSCEPTION IN CHILDREN AT THE KOMFO ANOKYE HOSPITAL, KUMASI, GHANA
}

\author{
F. A. ABANTANGA, M. AMOAH, A. O. ADEYINKA, B. NIMAKO and K. P. YANKEY
}

\begin{abstract}
Objective: To evaluate the role of pneumatic reduction in the management of intussusception in children in the setting of a sub-Saharan African nation.

Design: Prospective case series.

Setting: Tertiary care teaching hospital in Kumasi, Ghana.

Subjects: Forty four children, aged 4 months to 13 years, 28 boys and 16 girls, were admitted with a clinical diagnosis of intussusception and confirmed by ultrasonography.

Interventions: Twenty two children had air enema reduction of the intussusception attempted in the operation theatre under general anaesthesia. The average pressure used for air enema reduction of the intussusceptions was $110.4 \mathrm{~mm} \mathrm{Hg}$.

Main outcome measures: Success of pneumatic reduction, morbidity and mortality. Results: Overall air enema reduction of intussusception was successful in $59.1 \%$ of children who underwent this procedure. There were no deaths among children who had a successful air enema reduction of intussusception. One child (11.1\%) out of nine who had laparotomy done after a failed pneumatic reduction died. The average length of hospital stay was shorter in those with successful air enema reduction ( $3.8 \pm 2.3$ days, $95 \%$ Confidence Interval $[\mathrm{CI}]=2.4$ to 5.2 ) than those who had a laparotomy performed for manual reduction of the intussusception after a failed pneumatic reduction $(6.7 \pm$ 5.1 days, $95 \% \mathrm{CI}=33$ to 9.9 ).

Conclusion: Although the sample size is small, pneumatic reduction of intussusception in children without peritonitis is possible, practical, and reliable and must be tried first, preferably under general anaesthesia in our sub-region before proceeding to laparotomy in case of failure.
\end{abstract}

\section{INTRODUCTION}

Intussusception is a well-recognised cause of bowel obstruction in childhood. There is a paradigm shift in its management from immediate laparotomy after resuscitation to non-operative management. This sort of management of intussusception is rarely practised in our sub-region (1), although the advantages and benefits are numerous and include early discharge home, reduction in morbidity and mortality, absence of an abdominal wall scar and economic benefits to both the hospital and the parents of the child. In the developed world, air enema reduction (AER) is mostly done by paediatric radiologists in the radiology departments either under ultrasound guidance (25 ) or fluoroscopy $(6,7)$, most often, with or without sedation $(6,8)$. Using such facilities, they are able to determine immediately whether the intussusception has reduced or not. But the absence of these facilities should not be a hindrance to the use of AER in our sub-region. In mosthospitals in sub-Saharan African, paediatric radiologists are non-existent and therefore, this method of treatment can only be undertaken by paediatric surgery teams.

Consequently, the procedure of pneumatic reduction (PR) was performed by a paediatric surgery team, in an operating theatre, under general anaesthesia, without fluoroscopic and 
ultrasonographic assistance, to evaluate its efficacy in our sub-region in the light of the usual late presentation of our patients; also, the length of hospital stay and mortality rate were appraised.

\section{MATERIALS AND METHODS}

There were 44 children who had their intussusceptions confirmed clinically and by ultrasonography from January 2004 to December 2007. Imaging diagnosis of intussusception was performed on multipurpose ultrasound equipment Sonoline Sienna, Siemens Medical System.

Only $22(50 \%)$ children had AER of their intussusceptions attempted. The remaining $22(50 \%)$ children were excluded from the use of PR because of: peritonitis (12 cases), shock (5 cases), preference of the surgeon (3 cases), death in a child with a prolapsed intussusception while being resuscitated for possible surgery (1 case) and intestinal perforation (1 case); they were not included in the present analysis.

The method used is similar to the one detailed in the article by Wiersman et al (9), the difference being that we did not have any imaging facilities in theatre. Before the attempted reduction of theintussusception, the abdomen was always palpated under anaesthesia to confirm the presence of a mass as indicated on ultrasound. The set-up was such that the nasogastric (NG) tube passed during resuscitation of the patient was submerged in a kidney dish containing water.

Different pressures of airwere insufflated through the Foley catheter placed in the anal canal, leading to reduction or non-reduction of the intussusception. The lowest pressure used in an attempt to reduce intussusceptions was 60 and the highest $-140 \mathrm{~mm} \mathrm{Hg}$, with an average pressure of $110.4 \pm 23.7 \mathrm{~mm} \mathrm{Hg}(95 \%$ $\mathrm{CI}=99.5$ to 120.5$)$. Up to a maximum of five attempts, eachlasting for aboutfive minutes, weremadetoreduce the intussusceptions. The intussusception was said to have successfully reduced if there was i) a continuous free flow of air bubbles into the kidney dish through the NG tube; ii) a continuous lowering of the pressure seen on the gauge of the aneroid sphygmomanometer as the air flowed into the kidney dish, seen as bubbles of air; and iii) absence of a palpable mass after evacuation of much of the air through theanal orifice and the NG tube. If there was failure of reduction of the intussusception (in which case no air bubbles were seen escaping into the kidney dish with water) or if there was escape of air into the peritoneal cavity indicating a perforation in the bowel, then the abdomen remained grossly distended. In such instances, the attempt was abandoned and a laparotomy carried out immediately.

During the procedure the anaesthetist continuously ventilated the intubated child. Meanwhile the scrub nurse always had a prepared trolley waiting in case there was the need to perform a laparotomy.
Statistical analysis of means, standard deviation, confidence interval of various variables was performed using SPSS version 13.

\section{RESULTS}

Twenty two children, aged between 4 and 12 months (mean age $7.0 \pm 2.2$ months, $95 \% \mathrm{CI}=6.0$ to 8.0 ) (Figure 1) with a mean weight of $6.9 \pm 1.3 \mathrm{~kg}(95 \% \mathrm{CI}=6.2$ to 7.6) had pneumatic reduction done in an attempt to reduce their intussusceptions. There were 13 boys and nine girls, giving a ratio of 1.4 : 1 . The duration of the signs and symptoms of intussusception ranged from one day to six days, with an average delay in presentation from the beginning of the disease being $2.8 \pm 1.5$ days $(95 \% \mathrm{CI}=2.1$ to 3.4$)$. Intussusception was confirmed by abdominal ultrasound as an echogenic thick-walled oval-shaped mass with mixed echogenic invaginated bowels within it (Figure 2).

Of the 22 children, 13 had successful AER done and in nine, the procedure failed or was abandoned because of escape of air into the peritoneal cavity (Table 1).

Theprocedurescarried out for thenineunreduced intussusceptions during laparotomy are shown in Table 2. Of the children who had failed pneumatic reduction and needed laparotomy, five required resection of bowel (three - right hemicolectomy and two - subtotal colectomy) (Table 2). All these patients presented very late to hospital -more than 24 hours after the onset of the symptoms of intussusception.

The length of stay (LOS) in hospital for those undergoing PR was $3.8 \pm 2.3$ days $(95 \% \mathrm{CI}=2.4$ to 5.2$)$ and for those who had laparotomy done after failed PR, LOS was $6.7 \pm 3.7$ days $(95 \% \mathrm{C} 1=3.8$ to 9.5$)$. There were no deaths in the children with successful PR. One child died in the group who had surgery done after a failed air enema reduction. Overall mortality for this group of children was $4.5 \%$.

\section{Figure 1}

Age of children (in months) undergoing pneumatic reduction $(n=22)$

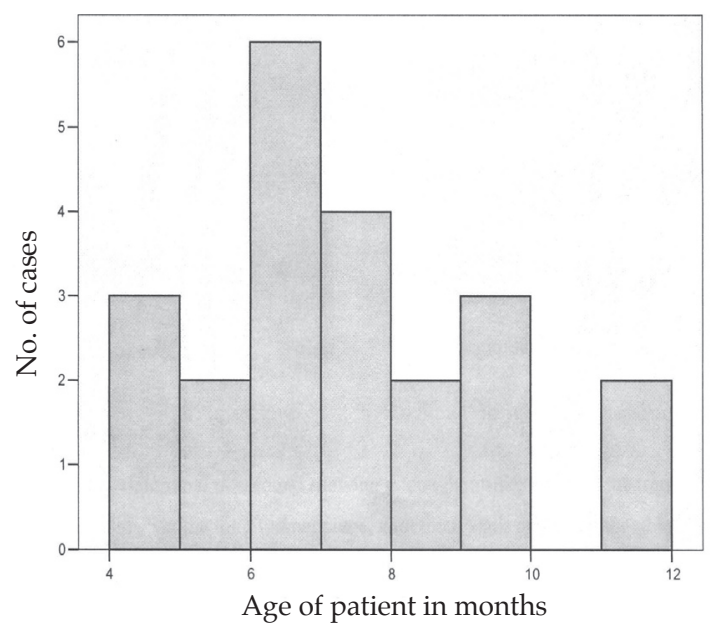




\section{Figure 2A \& B}

Abdominal ultrasound showing a 'doughnut-like mass' in the transverse plane and a "pseudokidney" in the longitudinal plane, with thick walls and invaginated bowel loops in an ileo-colic intussusception

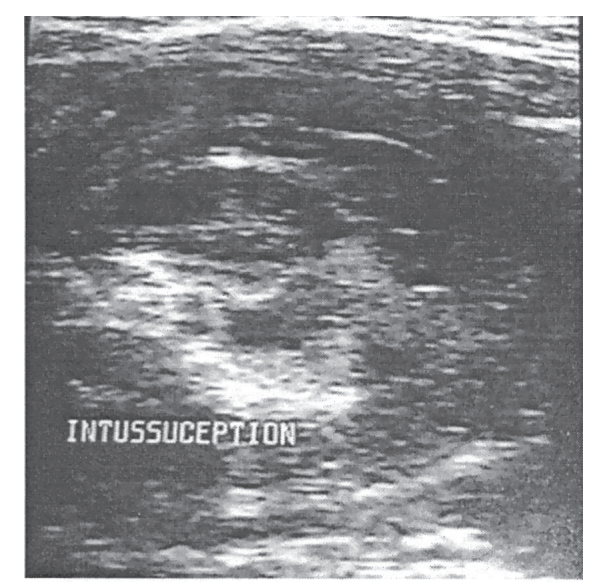

A. Transverse

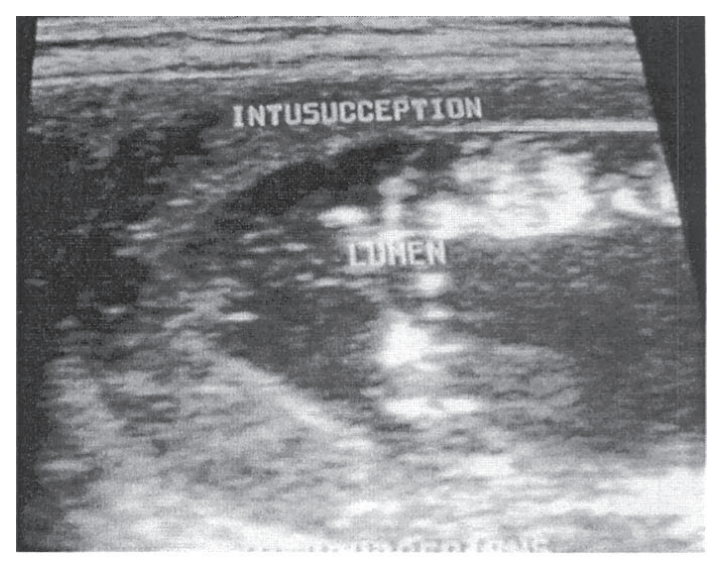

B. Longitudinal

Table 1

Success rate of pneumatic reduction $(n=22)$

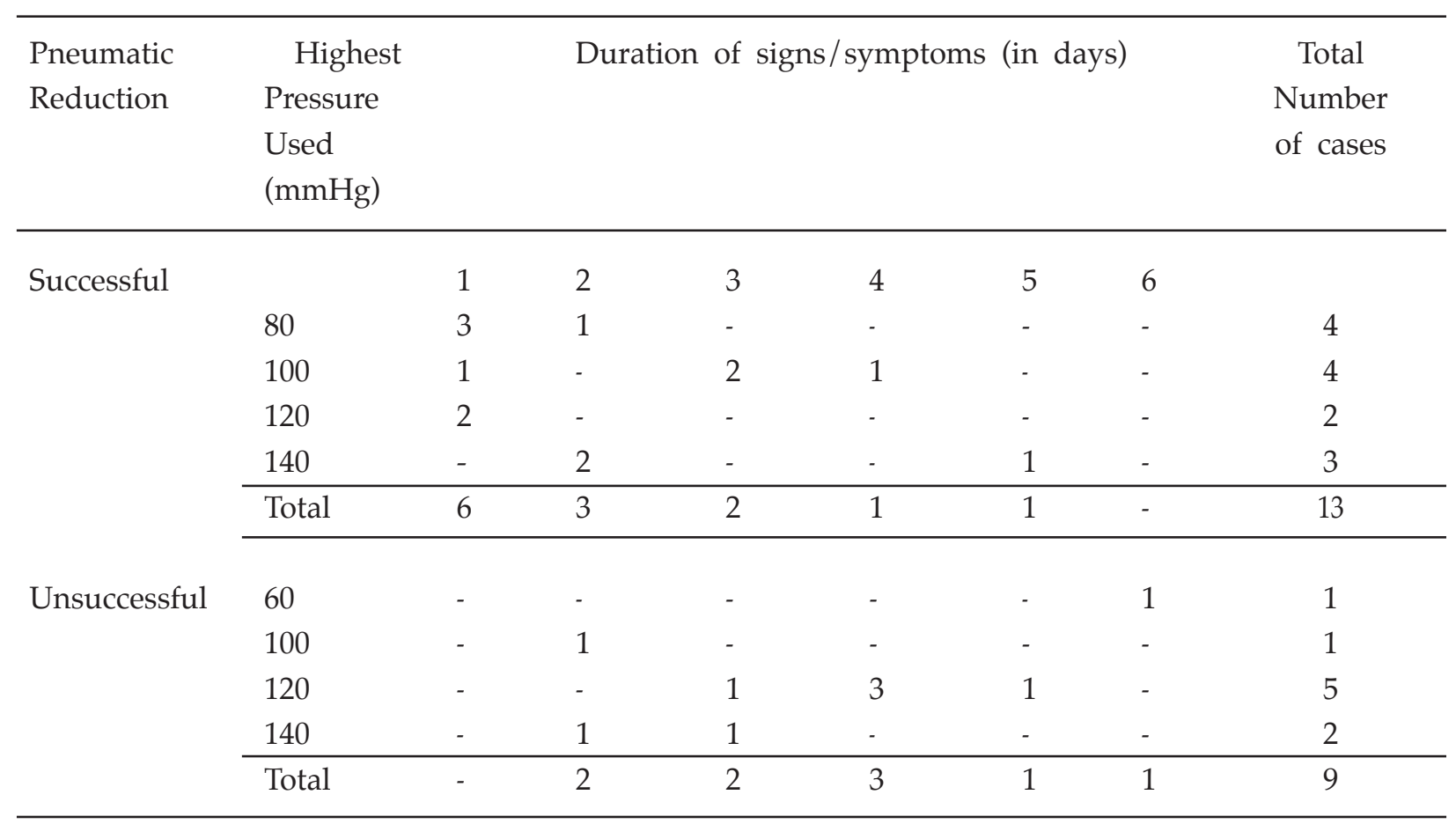


Table 2

Management of unreduced intussusceptions during laparotomy $(n=9)$

\begin{tabular}{|c|c|c|c|c|}
\hline $\begin{array}{l}\text { Type of } \\
\text { intussusception }\end{array}$ & $\begin{array}{l}\text { Duration of } \\
\text { symptoms }\end{array}$ & $\begin{array}{l}\text { Findings } \\
\text { performed }\end{array}$ & Procedure & Outcome \\
\hline Caeco-colic & 2 & $\begin{array}{l}\text { Oedematous } \\
\text { intussusception }\end{array}$ & $\begin{array}{l}\mathrm{MR}^{*} \text { with caecopexy } \\
\text { and repair of serosal tears }\end{array}$ & Lived \\
\hline Caeco-colic & 4 & $\begin{array}{l}\text { Oedematous } \\
\text { intussusception }\end{array}$ & $\begin{array}{l}\text { Difficult but } \\
\text { successful MR }\end{array}$ & Lived \\
\hline Caeco-colic & 4 & $\begin{array}{l}\text { Oedematous } \\
\text { intussusception }\end{array}$ & $\begin{array}{l}\text { Difficult but } \\
\text { successful MR }\end{array}$ & Lived \\
\hline Caeco-colic & 6 & $\begin{array}{l}\text { Two sigmoid and } \\
\text { one descending colon } \\
\text { perforations. Escape of } \\
\text { air into the peritoneal } \\
\text { cavity }\end{array}$ & $\begin{array}{l}\text { Subtotal colectomy with } \\
\text { ileosigmoid anastomosis }\end{array}$ & Lived \\
\hline Caeco-colic & 2 & $\begin{array}{l}\text { Oedematous bowel with } \\
\text { perforation noticed in the } \\
\text { sigmoid colon during MR. } \\
\text { No escape of air into the } \\
\text { peritoneal cavity during PR }\end{array}$ & $\begin{array}{l}\text { Subtotal } \\
\text { colectomy }\end{array}$ & Lived \\
\hline Caeco-colic & 4 & $\begin{array}{l}\text { Oedematous intussusception, } \\
\text { necrosis of the } \\
\text { intussusceptum }\end{array}$ & $\begin{array}{l}\text { Failed MR with } \\
\text { serosal tears; Right } \\
\text { hemicolectomy }\end{array}$ & Lived \\
\hline Ileo-colic & 5 & $\begin{array}{l}\text { Oedematous } \\
\text { intussusception with } \\
\text { multiple serosal tears }\end{array}$ & $\begin{array}{l}\text { Failed MR; Right } \\
\text { hemicolectomy }\end{array}$ & Lived \\
\hline Caeco-colic & 3 & $\begin{array}{l}\text { Oedematous } \\
\text { intussusception }\end{array}$ & $\begin{array}{l}\text { Difficult but } \\
\text { successful MR, } \\
\text { caecopexy }\end{array}$ & Lived \\
\hline Caeco-colic & 3 & $\begin{array}{l}\text { Oedematous and dark- } \\
\text { looking intussusception }\end{array}$ & $\begin{array}{l}\text { Failed MR Right } \\
\text { hemicolectomy, } \\
\text { ileo-transverse } \\
\text { colon anastomosis }\end{array}$ & $\begin{array}{l}\text { Died from } \\
\text { sepsis }\end{array}$ \\
\hline
\end{tabular}

$\mathrm{MR}=$ manual reduction of the intussusception.

\section{DISCUSSION}

World-wide, intussusception is the most common cause of strangulation-occlusion type of intestinal obstruction in childhood and remains a significant cause of morbidity in this age group. Left unrecognised or untreated, it can lead to bowel infarction, subsequentintestinalnecrosis, perforation, peritonitis and even death $(10,11)$. For the past 25 years or so, the treatment of choice of intussusception in stable children is by hydrostatic or air enema reduction under fluoroscopic or ultrasound guidance (2,
$4,7,8,12-14)$. This approach to the treatment of intussusception in children is practised in developed and some developing countries but not so much used in the sub-Saharan African countries, where we are lagging behind(1) despite its numerous advantages: early discharge home, reduction in morbidity and mortality, absence of an abdominal wall scar and the economic benefits to both the hospital and the parents of the child. In most centres, non-operative management of childhood intussusceptions is conducted by paediatric radiologists $(15,16)$ in the radiology departments. In most hospitals in sub- 
Saharan African, paediatric radiologists are nonexistent and therefore, this method of treatment can only be undertaken by paediaric surgery teams.

There are some contraindications in the use of either hydrostatic or air enema reduction of intussusception in children and most authors agree on them. These include signs of bowel perforation, peritonitis, shock or a clinically unstable child $(4,8)$. Also most clinicians whouse these methods of treating patients with intussusception agree that pneumatic reduction is faster, easier, cleaner and is associated with higher success rate than the use of barium, water or normal saline for the same purpose $(8,12,17)$.

Despite the fact that most of our patients presented late, more than 24 hours after the onset of signs / symptoms of the disease, we were still able to reduce some of the intussusceptions in the late comers. About $72.7 \%$ reported to hospital after 24 hours; the rest came within 24 hours of the appearance of the symptoms. And for all those who came within 24 hours of the appearance of symptoms, pneumatic reduction was $100 \%$ successful at pressures not exceeding $120 \mathrm{~mm} \mathrm{Hg}$.

From the aforementioned, we advocate that in our sub-region, all intussusceptions should be reduced under general anaesthesia in the operating theatre (with the child intubated). This way, the child is kept constantly ventilated keeping the oxygen saturation in the normal range and allowing the surgeon to work maximally. In the case of failure of reduction of the intussusception or escape of air into the peritoneal cavity, the procedure is immediately stopped and a laparotomy done. For example, in our group of patients, an attempted air enema reduction of the intussusception in the child who presented on the $6^{\text {th }}$ day from the beginning of the disease was abandoned at a pressure of $60 \mathrm{~mm} \mathrm{Hg}$ because it was noticed that the insufflated air escaped into the peritoneal cavity (The preoperative chest radiograph of this child did not show air under the diaphragm patient 4 of Table2). Laparotomy revealed perforations in the sigmoid and descending colons with necrotic edges. The child survived the surgery. It is known that in such situations abdominal compartment syndrome (12) can occur as a result of the gross abdominal distension from the pneumoperitoneum with resultant splinting of the diaphragm leading to respiratory distress syndrome(13). In the case where such a patient is to be transported to the operating theatre from the radiology unit, the outcome can be fatal and to forestall this we suggest that under our conditions, pneumatic reduction should be done in the operating theatre and the procedure immediately abandoned if it is noticed that the insufflated air is escaping into the peritoneal cavity. In cases where compartment syndromehas developed, some authors suggestimmediateintervention by paracentesis using a 14-gauge needle $(12,13)$, which is said to be life- saving, before transporting the child to the operating theatre from the radiology unit.

Plain abdominal radiograph, although of poor sensitivity in the detection of intussusception $(11,18)$, is useful in the initial screening once clinical suspicion is made and will show small bowel distension, adynamic ileus(4), and little gas distal to the head of intussusceptum(19). It will also show air under the diaphragm(2), if present. On the other hand, ultrasound is cheap and non-invasive and has no ionizing radiation, and is useful in making alternative diagnosis. Intussusception usually appears as a 'doughnut-like mass' in the transverse plane and as a "pseudokidney" in the longitudinal plane(4) with thick walls and invaginated bowel loops, mostly localised in the right hypochondrium in theileo-colic variety (Figure 2). Majority of our cases in this study were of the ileo-colic.

The course of reduction can be monitored by either ultrasound or fluoroscopy. Ultrasound-guided pneumatic reduction has been shown to have a high success rate (2); the procedure is considered to be successful when an ultrasound scan shows the disappearance of the intussusceptum and the oedematous terminal ileum with an abrupt transition into the normal bowel(2). However as has been demonstrated in this study, pneumatic reduction of childhood intussusception in the operating theatre is possible without the benefit of fluoroscopic or ultrasound guidance. Successful reduction in our situation was controlled by the continuous escape of air bubbles through an NG tube dipped into a kidney dish containing water, the lowering of the pressure on the gauge of the aneroid sphygmomanometer and the absence of the palpable mass felt at the beginning of the procedure when the child was anaesthetised and intubated. Using this method we were able to reduce $59.1 \%$ of the intussusceptions that underwent pneumatic reduction in spite of the fact that over $72.7 \%$ of our patients reported to hospital later than 24 hours after the onset of symptoms. There were no deaths among the children who had a successful air enema reduction of the intussusception; such children also left hospital earlier for home than those who had a failed procedure and had to have a laparotomy carried out. There was one death in the last group of patients.

In conclusion, the procedure of pneumatic reduction was performed on clinically and ultrasonographically diagnosed cases of intussusception by a paediatric surgery team, in an operating theatre, under general anaesthesia, but without fluoroscopic and ultrasound guidance during the course of reduction. The efficacy of the procedure in our sub-region, in the light of the usual late presentation of our patients, and the length of hospital stay and mortality rate were appraised and found to be acceptable. Despite the small numbers 
presented here, we believe that air enema reduction of intussusceptions in our sub-region, in the absence of fluoroscopic and ultrasound machines, is feasible and should be the treatment of choice for all intussusceptions even when they report late to hospital (except where there are contraindications). We think the procedure is easy to learn, quick to perform and very clean and should be performed in an operating theatre under our conditions.

\section{REFERENCES}

1. Archibong, A. E. Conservative reduction of intussusception in children. Why are we lagging behind? Global J. Med. Sci. 2007; 6: 1-3.

2. Yoon, C.H., Kim, H. J. and Goo, H. W. Intussusception in children: US-guided pneumatic reduction-initial experience. Radilogy. 2001; 218: 85-88.

3. Go, L., Zu, H., Wang, S., et al. Sonographic guidance of air enema for intussusception reduction in children. Pediatr. Radiol. 2000;30: 339-342.

4. Ko, H. S., Schenk, J. P., Troger, J. and Rohrschneider, W. K. Current radiological management of intussusception in children. European Radiol. 2007; 17: 2411-2421.

5. Krishnakumar, H. and Umamaheshwari, S. Ultrasound guided hydrostatic reduction in the management of intussusception. Indian. J. Pediatr. 2006; 7: 217-220.

6. Okazaki, T., Ogasawara, Y., Nakazawa, N. et al. Reduction of intussusception in infants by a pediatric surgical team: improvement in safety and outcome. Pediatr. Surg. Intl. 2006; 22: 897-900.

7. Bajaj,L. and Roback, M.G.Postreduction management of intussusception in a children's hospital emergency department. Pediatr. 2003; 112: 1302-1307.

8. Heenan, S. D., Kyriou, J., Fitzgerald, M. and Adam, E. J. Effective dose at pneumatic reduction of paediatric intussusception. Clin. Radiol. 2000; 55: 811-816.

9. Wiersma, R. and Hadley, G. P. Minimizing surgery in complicated intussusceptions in the Third World. Pediatr. Surg. Intl. 2004; 20: 215-217.

10. Parashar, U. D., Holman, R. C., Cummings, K. C.et al. Trends in intussusception-associated hospitalizations and deaths among US infants. Pediatr. 2000; 106: 1413-1421.

11. Applegate, K. Clinically suspected intussusception in children: evidence-based review and self-assessment module. A. J. R Intergr. Imaging 2005; 185: S175-S183.

12. Ng, E., Kim, H. B., Lillehei, C. W. and Seefelder, C. Life threatening tension pneumoperitoneumfromintestinal perforation during air reduction of intussusception. Paediatr. Anaesthesia. 2002; 12: 798-780.

13. Maoate, K. and Beasley, S. W. Perforation during gas reduction of intussusception. Pediatr. Surg. Intl. 1998; 14: 168-170.

14. Khanna, G. and Applegate, K. Ultrasound guided intussusception reduction: are we there yet? [Review]. Abdominal Imaging. 2008; 33: 38-40.

15. Britton, I. and Wilkinson, A. G. Ultrasound features of intussusception predicting outcome of air enema. Pediatr. Radiol. 1999; 29: 705-710.

16. Kornecki, A., Daneman, A., Navaro, O., et al Spontaneous reduction of intussusception: clinical spectrum, management and outcome. Pediatr. RadioI. 2000; 30: 58-63.

17. Cohen, M. D. From air to barium and back to air reduction of intussusception in children. Pediatr. Radiol. 2002; 32: 74.

18. Hernandez, J. A., Swischuk, L. E. and Angel, C. A. Validity of plain films in intussusception. Emerg. Radiol. 2004; 10: 323-326.

19. West, K. W., Stephens, B., Vane, D. W. and Grosfeld, J. L. Intussusception: current management in infants and children. Surgery. 1987; 102: 704-710. 